\title{
Assessment of the trophic state of a water body
}

\author{
O. Ravera'
}

The difference in point of view between the limnologist and the public on the trophic level of a water body is discussed in relation to actions promoted by administrators. Numerical and probabilistic classification, models, "trophic indices" and biological indicators for assessing the trophic degree of lakes are briefly illustrated.

The contribution of the OECD's " Eutrophication programme " (1971-1979) to the assessment of the trophic degree of lakes is relevant. In agreement with Vollenweider's model, this programme adopted as a guide-line the relationship between phosphorus load from the watershed and the phosphorus concentration in the lake water and between this concentration and that of phytoplankton, expressed as chlorophyll concentration. These relationships are statistically significant but a certain number of lakes deviate from them. These deviations and their causes are considered; for example, nutrient release from sediments, short hydrological relention time, high mineral turbidity, excessive development of macrophytes, non available forms of phosphorus, high predation pressure by zooplankton. The opportunity to take into considération the influence of toxic pollutants in eutrophicated water bodies is emphasized. To compare the trophic degree of lakes laying at different latitudes, the pattern of solar radiation and temperature should be considered, in addition to nutrient loading. As a case study to show the difficulties involved in assessing the trophic degree of a lake and identifying the causes of its evolution the results from a study carried out from 1969 to 1980 on the small alpine lake Monate (Northern Italy) are discussed.

Evaluation de l'état trophique d'un plan d'eau.

La perception du niveau trophique d'urt plan d'eau par les limnologistes et par le public est ḋiscutée par rapport aux actions engagées par les administrations. Les critères d'évaluation du niveau trophique des lacs-classifications, modèles, indices trophiques, indicateurs biologiques - sont brièvement illustrés.

En accord avec le modèle de Vollenweider, le a Programme Eutrophisation " de l'O.C.D.E. (1971-1979) a adopté comme fondement les relations ent re la charge de phosphore, les concentrations de cet élément dans l'eau et la biomasse de phy to exprimée en concentration de chlorophylle. Ces relations sont statistiquement significatives, mais un certain nombre de lacs font exception. Ces exceptions et leur cause (p. ex relargage du phosphore par les sédiments, faible temps de rétention hydraulique, forte turbidité minérale, développement excessit de macrophytes, biodisponibilité du phosphore, forte pression prédatrice du zooplancton) sont évoquées. Le rayonnement solaire et la température doivent également être pris en considération pour comparer le niveau trophique de lacs sous différentes latitudes. Les difficultés rencontrées pour évaluer le degré de trophie d'un lac et identifier les causes de son évolution sont illustrées par des résultats d'une étude conduite en 1969 et en 1980 sur un petit lac alpin du nord de I'Italie, le lac Monate.

The trophic level of a lake may be judged scientifically, that is from the limnologists point of view. as well as by its impact on the public. Limnologists judge the trophic level considering the lake as an ecosystem and use parameters such as primary production, nutrients, oxygen concentration and popu. lation density and structure of phytoplankton. Public awareness relates to colour, transparency,

1. Department of Physical and Natural Sciences. Commission of the Furopean Communities. J.R.C. 21020 ISPRA (VARESE) ITALY. smell and taste of the water, frequency and importance of algal blooms, increased extension of the area with macrophytes and yield and quality of fish.

There is agreement between the parameters considered, but this is not always perfect : for example, high transparency is an index of pure water for the public but not always for the scientist. Indeed, in lakes polluted by toxic substances water transparency may be high but population density of phytoplankton low. In addition, nutrient concentration 
may be high but phytoplankton density low when predation by zooplankton is not controlled by planktivorous fish.

Administrators must invoke action with a scientific basis for recovering water bodies with high trophic level but obviously cannot disregard the criteria perceived by the public. For this reason certain measures exist which produce a real reduction in the trophic level of water bodies together with others which only apparently ameliorate water qua. lity and consequently may be termed " cosmetic". Examples of the latter type are the eradication of macrophytes and bubbling air (or oxygen) into the water during critical periods of the year. These " cosmetic " measures must not be noxious to the water ecosystem (e. g. introduction of algicides or other toxic chemicals) and must be used with other actions which effectively and permanently decrease the trophic degree of the water body, for exemple the reduction of nutrient load.

This paper is limited to the concepts and methods for assessing the trophic state of water bodies and does not take in consideration other important aspects of the eutrophication problem discussed in preceeding papers, such as, the diversity and stability of the community in relation to the trophic evolution of a lake (Ravera 1979).

The assessment of the trophic state of a lake is essential for any study of its evolution and metabolism and for planning actions to protect and, if the lake is overfertilized, to recover it.

For practical purposes well defined limits between successive levels on a numerical trophic scale are very useful, that is a classification of lakes according to their trophic level. Vollenweider's classification (1979) is one of the most recent and realistic approaches because the limits of this classification are based pragmatically on a large amount of data, whereas in the other classification categories are established a priori.

In order to facilitate communication with the public and administrators, a wide variety of numerical " trophic indices " has been developed (e.g. Brezonik \& al. 1971 ; Uhlman \& al. 1976 ; Carlson 1977). These indices are based one or few parameters associated with the trophic evolution of the water body and must be easily measurable (e.g.) water transparency, chlorophyll and phosphorus concentrations, electrical conductivity). Because the evolution of a lake, from the oligotrophic to the eutrophic stage, is a "continuum ", the most evident disadvantage of the "trophic indices" consists in establishing well defined values between successive trophic levels. For this reason Vollenweider (1979) proposed a more natural classification based on the probability that a given lake, with a certain mean concentration of phosphorus and chlorophyll, will belong to a given trophic category (e.g. oligotrophic).

Vollenweider $(1969,1975)$ developed a « inputoutput " model applying the mass-balance concept and considering total lake water volume with homogeneous nutrient concentration (i.e. phosphorus). Nutrient concentration in lake water is considered as a function of the loading rate in relation to the average depth of the lake and its mean hydrologi. cal renewal time. This model has been adopted as a guide-line to predict the trophic level of lakes studied in the framework of the OECD's " Eutrophication Programme"(1971-1979). Other authors (O'Melia 1972 ; Imboden 1974) developed a more realistic but more complex model taking into condideration the nutrient released by the sediments as well as dividing the water body into two layers. Further more sophisticated models are based on the principles adopted by the overmentioned authors.

For assessing the trophic state of a water body and its evolution many physical and chemical parameters are very useful. For practical purposes a limited number of important parameters must be identified and measured during "critical "periods of the year (e.g. spring overturn) and at " critical " layers (e.g. epilimnion, metalimnion, hypolimnion). For example, in the framework of the OECD's " Eutrophication Programme " comparing more than 200 water bodies with very different trophic levels it was necessary to chose a series of important parameters (essential parameters) which all the laboratories involved in this programme could measure. In addition, other parameters (desirable) were recommended and a sampling strategy related to season (e.g. spring overturn) frequency and depth (e.g. euphotic zone) has been developed. For example, temperature, $\mathrm{pH}$, oxygen, total phosphorus and orthophosphate concentration were classified as essential parameters, whereas others such as primary productivity were considered desirable.

Because the analyses on different lakes were done at different laboratories the standardization of 
analytical methods was very important. To reach this goal in some projects of the OECD's Programme (e.g. Alpine Project) ring-tests were done. Consequently, scattering between data from different laboratories could be tested and, the laboratories had the possibility of improving their methods and equipment.

Nutrient loading (particularly for phosphorus and nitrogen) was one of the most important topics of the OECD's Programme and it was evaluated from the chemical analysis of the tributaries as well as from investigations. The first method is more accurate, the latter has the advantage of estimating the relative contributions of nutrients from different sources of nutrients (e.g. agriculture, industrial effluents). The most useful information was obtained when both methods were adopted and for more than one year.

The contribution of dry and wet fall-out to total nutrient load may be relevant and, if so, must be accu rately determined. Agriculture and urban runoff are the most common non-point sources of nutrients. Urban runoff may contain suspended solids up to $2 \mathrm{gr} / \mathrm{l}$, total phosphorus as high as $15 \mathrm{mg} / 1$ and several thousand coliforms per $100 \mathrm{ml}$. Rural runoff contains suspended particles, nutrients, biocides and microorganisms (Abernathy 1981). Because nutrient load from non-point sources is difficult to evaluate, information on this important subject is scarce.

In addition to physical and chemical parameters, single species or associations of organisms have been used as a indicators of trophy ". Because one species may be composed by different ecotypes, with varied tolerance to certain environmental characteristics, the use of single species as indicators of trophy may be hazardous. Phytoplankton structure and biomass may be the most useful indicators of the trophic state of a water body, because they depend directly upon the quality and quantity of nutrient available. The successive trophic links of predator-prey food chain (e.g. zooplankton, fish) depend ultimately upon the phytoplankton and therefore indirectly upon nutrients (e.g. Ravera 1980). For this reason, organisms from the detritous food chain should be theoretically less indicative than phytoplankton. Macrophytes are controlled by nutrients just as phytoplankton, but their distribu$t$ ion is also strictly influenced by the morphological characteristics of the lakeshore.
Research carried out in the framework of the OECD's \& Eutrophication Programme » from 1971 to 1979 improved our knowledge of the causes, effects and the correctives concerning eutrophication of lakes and impoundments. From these studies positive relationships between phosphorus load from the watershed and phosphorus and chlorophyll concentrations in lake water were found.

These relationships are statistically significative, but certain lakes deviate from them. These exceptions resulted from factors related to the morphological and hydrological characteristics of the lake, climatic factors, community structure of the ecosystem and other factors. For example, a quantity of phosphate and other nutrients present in the sediments of certain lakes is released into the water under anaerobic conditions. Some of these nutrients may enter the trophogenic layer and be assimilated by phytoplankton. If this quantity of nutrients is significant, in relation to the external nutrient load, the relationship between the latter and chlorophyll concentration cannot be predicted by the Vollenweider's model. The transfer of nutrients from sedj. ments to the algal populations is obviously more relavant in shallow than in deep lakes (Ravera 1981). In few lakes the critical element is nitrogen and not phosphorus, in others excessive development of macrophytes prevents phytoplankton blooms. In addition, if the renewal time of the lake water is too short (as in some impoundments), there is no rela. tionship between phosphorus load and chlorophyll concentration. Sometimes phytoplankton biomass is small, and chlorophyll concentration low, in spite of relatively high phosphorus concentrations in lake water. In some lakes this is due to high turbidity resulting from the abundance of mineral suspended particles which depresses the growth of phytoplankton populations. The same effect is obtained if a significant fraction of the total phosphorus is in a chemical form (e.g. apatite) not available to the phytoplankton (e.g. Oglesby \& al. 1978 ; Shaffner \& al. 1979). In addition, high predation pressure by zooplankton on phytoplankton may mask the nutrient effect; herbivores graze a large part of the net production and. consequently, phytoplankton standing crop and chlorophyll concentration are low. The introduction of planktivorous $f$ ish in an environment with these characteristics produces a decrease of the zooplankton and, consequently, an increase of the phytoplankton biomass (e.g. Ravera 
1980). Because several industrial and agricultural chemical have a detrimental effect on phytoplankton, the relationship between phosphorus concentration in lake water and chlorophyll may be masked by toxic compounds. On the other hand, some heavy metals (such as $\mathrm{Co}, \mathrm{Cu}, \mathrm{Zn}$ ), considered as pollutants when concentrate in effluents, may become oligoelements after being diluted in lake waters and, therefore, improve the phytoplankton growth-rate. "The most general effect of heavy metals in the modification of phytoplankton structure ; for example, low concentrations of copper, seem, to depress the blue green algae population, whereas mercury increases the population growth of this taxon killing the greatest part of the other phytoplankton groups ". In a addition, in certain quantities, hydrocarbons may present an available substrate for bac. terial growth, whereas biocides may decrease zooplankton predation of the phytoplankton.

In " inclosure " experiments (" microecosystem ") effects produced by heavy metals on phytoplankton have been noted, but they were wery small, if compared with those obtained with the same concentrations in the laboratory. In addition, a degree of recovery has been observed a few days after the introduction of the toxic metal into the "enclosure". This demonstrates that a concentration of a toxic pollutant seems to produce smaller effects in the natural environment than under laboratory conditions (Ravera et al. 1980 ; Kerrison et al. 1980). This is due, at least for the metals, to the adsorption of the pollutant on to suspended particles and to che. lation by humic acids and other substance. Consequently the amount of pollutant available to phytoplankton is comparatively small.

The combined effects of toxic pollutants and eutrophication is an interesting topic for future research, but up to now, information on this sub. ject is limited. The greatest part of the studies on eutrophic lakes do not take into account toxic pollution (e.g. OECD's " Eutrophication Programme "). However, in a large number of lakes the concentra. tion of toxic substances is low and, consequently. the biological consequences do not seem to be very important. In a few lakes (e.g. Lake Orta, Northern Italy), after an accident or because the watershed lays in a mining area, the effects of toxic pollution have been catastrophic. In addition, from the limited information available, it seems that in eutrophic waters the effects of toxic substances are reduced, probably by the abundance of suspended particles and humic acids. For example, oligotrophic lakes are more affected by mercury than are eutrophic lakes. In conclusion, to take into account toxic pollutants in studies on eutrophication is important, but does not seem to be essential for most lakes. This does not exclude that there is a need for more information on the influence of low concentrations of toxic substances on the genetics and behaviour and reproduction of freshwater organisms in natural environments with various trophic levels. In addition, low concentrations of certain pollutants in water may accumulate through the food-chain, and become dangerous to man who feeds on the animals at the top of the aquatic chain (e.g. fish).

To complete the assessment of lake conditions, the influence of natural factors affecting eutrophication processes (e.g. lake morphology, lithology of the watershed, meteorology) must be evaluated and distinguished from those resulting from human activities (e.g. nutrient enrichment from the effluents). This distinction is fundamental when predicting the level of lake recovery which may be obtained in rela. tion to the correctives applied. In addition, the influence of correctives (e.g. waste water treatment plants) must also be evaluated. It is clear that the waste water treatment plant with the phosphate stripping (3rd stage treatment) is the best method of reducing the external nutrient load to the water body considered as a whole. On the other hand, because the removal of nutrients is never of $100 \%$, a certain aliquot of nutrients and chemicals, used to precipitate phosphates, is concentrated at the discharge point. The effects observed in the discharge area are obviously more deleterious if toxic substances are present in the treated waters as occured in Lake Geneva in the Lausanne area (Laurent 1973).

The assessment of trophic condition must also take into account the present and future uses of the water body. Consequently, the physical, chemical and biological characteristics of the water must be also judged from the point of view of water quality standards for drinking, bathing, fishing and irrigation.

To show the difficulties involved in assessing the trophic state of a water body and identifying the causes of its evolution, Lake Monate (Northern Italy) may be considered as an example. The maximum depth of Lake Monate is $36 \mathrm{~m}$, mean depth $18 \mathrm{~m}$ and its surface area $2.5 \mathrm{~km}^{2}$. Because the surface of its 
watershed is relatively small $\left(5.5 \mathrm{~km}^{2}\right.$ excluded the lake area), the load of water and mineral substances is small; in fact the mean electrical conductivity values of the lake water are always lower than $100_{\mu} \mathrm{S} \mathrm{cm}^{-1}$ (at $18^{\circ} \mathrm{C}$ ). The lake does not receive tributaries but only rainfall, but probably a certain amount of underground water. The lake has an outlet (Acquanera River) with an outflow of $0.2 \mathrm{~m}^{3 /} / \mathrm{sec}$.

Lake Monate has been studied over two periods : the first from 1969 to 1971 , the second from 1978 to 1980 . During the first period the mean concentration of total phosphorus was $5 \mathrm{mg} / \mathrm{m}^{3}$, whereas in the second it had increased to $50 \mathrm{mg} / \mathrm{m}^{3}$. Unfortunately, orthophosphates were not analyzed in the first period, but in the second they attained a mean value of $11 \mathrm{mg} / \mathrm{m}^{3}$. In conclusion, total phosphorus increased 10 times during less than ten years, whereas orthophosphates increased 2 times, assuming that all phosphorus during the period 1969-1971 was in the mineral form. From 1969-1971 to 1978.1980 Kjeldahl-N increased 3 times that is from 100 $\mathrm{mg} / \mathrm{m}^{3}$ to $300 \mathrm{mg} / \mathrm{m}^{3}$. The mean chlorophyll concentration for the $1969-1971$ period was $50 \mathrm{mg} / \mathrm{m}^{2}$; with a maximum in spring of $27 \mathrm{mg} / \mathrm{m}^{2}$; with a maximum in spring of $27 \mathrm{mg} / \mathrm{m}^{3}$ and a minimum in winter of $0.5 \mathrm{mg}$. In the period 1978-1980 no significant variation in chlorophyll concentration and seasonal pattern was noted. Transparency, $\mathrm{pH}$ values and oxygen concentration did not change from 1969 to 1980 .

From this information two questions arise : 1) why has the phosphorus concentration in the lake water increased ? 2) why the increase of phosphorus concentration do not produce an increase in chlorophyll concentration, that is of phytoplankton biomass?

The increase in the number of inhabitants settled in the watershed is too low to account for an increase in total phosphorus of 10 times in lake water and the use of the watershed was practically the same during the two periods considered. One source of the phosphorus present in the lake water could be the sediments which are very rich in organic material $(25 \%)$. This may account for the phosphorus increase, but phosphorus released from the sediment is in the mineral form, whereas the most of the phosphorus in lake water is organic. The increase in available phosphorus (orthophosphates) is small, if compared with that of total phosphorus. but in a lake poor in this element a significant increase of phytoplankton may be expected from a small increase in orthophosphates. Chlorophyll con- centration maintained statistically the same value during the two periods considered. The presence of toxic pollutants or/and an increase in turbidity by silting are excluded and, consequently, these cannot be the factors controlling phytoplankton growth.

From these considerations the following hypothesis seems to be most probable. During the last years a comparatively larger amount of mineral phosphorus was available and the growth-rate of phytoplankton was accelerated. This increase may have supported a greater population density of zooplankton which fed on the "surplus " of the net production and as a result the phytoplankton biomass (measured by chlorophyli) remained constant. To ascertain the variations in the zooplankton biomass a comparison between a zooplankton sample collected in 1969-1971 and those collected this year will be done. Experiments in " enclosures " are in progress to evaluate the predation pressure of zooplankton on phytoplankton in Lake Monate.

The case of Lake Monate shows that the assessment of the trophic state of certain lakes and their causes needs accurate studies and the the most commonly used "trophic indices" and/or simple models cannot be applied.

\section{Conclusions}

"Trophic indices " may be used to obtain a preliminary idea of the probable trophic state of a lake. They may be useful for communicating the trophic conditions of a water body, its evolution and eventual recovery to the public and administrators in comprehendable way. It is clear that the strategy for recovering a lake must be based on more scientific information.

"Biological indicators" may be useful in some cases, but up to now our knowledge on this subject is too limited to be applied to practical problems such as actions for recovering an eutrophicated lake.

Phytoplankton growth is controlled, in addition to the nutrients, by light and temperature. As a consequence, more attention must be payed to the combined effects of these parameters and, particularly, to extrapolating the results obtained from studies on lakes laying in temperate zones to those in tropical areas. 
In my opinion, the trophic state of lakes should be assessed according to the conclusions drawn up from the OECD's "Eutrophication Programme". that is on the relationships between phosphorus load, phosphorus concentration and chlorophyll concentration. This relationship, permits the assessment of the trophic state of the lake, and facilitates the prediction of what must be done to reduce the phosphorus load and improve the lake conditions. When these relationships cannot be applied, the cause must be fourd from one or more of the dis. cussed exceptions, such as silting, internal nutrient load, overgrazing by zooplankton. This sequence of studies is needed not only for assessing the trophic state of a water body and its causes but also for planning the more opportune correctives and evaluating their effects. Indeed, these correctives must be obviously chosen with a knowledge of the physical, chemical and biological characteristics of the water body, the nature of its watershed, and in relation to the foreseen uses of the lake and the development of human activities in the watershed area.

\section{References}

Abernathy (A.R.). 1981. - Oxygen consuming organics in nonpoint source runolf. Project Summary EPA-600/53-81-033.

Brezonik (P.L.) \& Shannon (E.E.). 1971. - Trophic state of lakes in north central Florida. Florida water Resources Research Center Publ. 13: 102 pp.

Carlson (R.E.). 1971. - A trophic state index for lakes. Limnol. Oceanogr. $22: 361-369$.
Imboden (D.M.1. 1974 - Phosphorus models of lake eutrophi. cation. Limnol. Oceanogr: 19:297.304.

Kerrison (P.H.), Sprocati (A.R.), Ravera (O.) \& Amantini (L.). - 1980. Effects of Cadmium on an aquatic community using artificial enclosures. Environmental Technol. Letters 1: 169.176

Laurent (P.). 1973. - Les pollutions qui ne résultent pas des rejels de substances toxiques ou Eermentescibles. Economie et Medi. cine Animales : 14:129-139

Oglesby (R.T.) \& Schaffner (W.R.) 1978 - Phosphorus loadings to lakes and some of their responses. Part. 2 Regression models of summer phvtoplarkton standing crops, winter total $P$, and transparency of New York lakes with known phosphorus loa. dings. Limnol Oceanogr. $23: 135.145$.

O'Melia (R.R.) 1972. - An approach to the modeling of lakes. Schwei: 2. Hodrol. $34: 1.33$.

Ravera (O.). - Some selected examples of eutrophicated European lakes. VI Session of European Environmental Summerschool EA. Jülich, May 28 - June 8, 1979 (in press).

Ravera (O.). 1980. - The influence of the nutrient enrichment on freshwater zooplankton. Int. Symposium on inland waters and lake restoration (Sepi. 8-12, 1980) Portland, USA, EPA 440/5-81-010: $210-217$.

Ravera (O.) \& Annoni (D.). 1980. - Effetti ecologici del rame stu diati per mezzo di un ecosistema sperimentale. in : Atti III Congresso A.I.O.L., (Sorrento $18-20 / \mathrm{XII} / 78$ ) : 417-421.

Ravera (O.). 1981. - Effects of nutrient enrichment of water bodies and its correctives. in : Water Indusiry 81 Intematio nal Conference, Brighton, U.K., June 1981 - CEP Consultants Lid, $1981: 63-69$.

Schaffner (W.R.) \& Oglesbr (R.T.). 1978. - Phosphorus loadings to lakes and some of their responses. Part 1 . A new calculation of phosphorus loading and its application to 13 New York lakes. Limnol. Oceanogr. $23: 120-134$.

Uhlmann (D.) \& Hrbacek (J.). 1976 - Kriterien der Eutrophie stehender Gewässer. Limnologica 10 : 245-253.

Vollerweider (R.A.). 1969. - Possibilities and limits of elementary budget models for lakes. Arch. Hydrobiol. $66: 1.36$.

Vollenweider (R.A.). 1979.-Das Nährstoffbelastungskonzept als Grundlage fur den externen Eingriff in den Eutrophierungsprozess stehender Gewasser und Talsperren. Z. f. Wasser-und Abwasser-Forsching, 12 Jahrgang $\mathrm{Nr}$. $2 / 79$. 